\title{
Articles
}

\section{Density Functional Theory Study of Acetonitrile - Water Clusters: Structures and Infrared Frequency Shifts}

\author{
Doo-Sik Ahn" and Sungul Lee* \\ College of Environmental Science and Applied Chemistry (BK21). Kumghee Universitw. Kumghi 449-701. Korea \\ "E-mail: sieeiákhu.achr \\ Received Jonuary 29.2007
}

\begin{abstract}
We present calculations for the acetonitrile - water clusters to examine the nature of interactions in the mixed clusters. We calculate conformers of various composition, either of $\sigma$-type (-OH and $-\mathrm{CN}$ binding linearly) or $\pi$-type (-OH and - $\mathrm{CN}$ interacting perpendicularly) structures for the acetonitrile - water clusters. We predict that the IR frequency of the proton-accepting $\mathrm{C} \equiv \mathrm{N}$ stretching mode red-shifts in the $\sigma$-type clusters and blueshifts in $\pi$-type conformers, whereas the proton-donating $-\mathrm{OH}$ stretching frequency red-shifts in all cases. We find that this intriguing pattern also applies to the acetonitrile - water clusters of various molar ratio.
\end{abstract}

Key Words : Acetonitrile. Water. Mixed cluster. IR frequency

\section{Introduction}

Clusters ${ }^{1.2}$ are of fundamental inportance. because they lie between the free molecule and the solute molecule in the condensed phase. Although their physicochenical properties are usually not easily predictable from those of the solute and the solvent molecules. studying the clusters may shed considerable light on the effects of solvation on the structure and reaction of the solute molecule on the molecular scale. In the cluster model, or the "supramolecular approach", the effects of "microsolvation" their properties as a function of the number and arrangement of solvent molecules around the solute.

Although large amount of information has been accumulated for the structures of the clusters. most investigations were focused either on pure clusters or those consisting of solute molecule and a number of solvent molecules. Recent studies of aromatic alcohol - water clusters, ${ }^{1(i .14}$ benzonitrile - water complexes ${ }^{15.16}$ and benzene - acetonitrile clusters ${ }^{17}$ are also of the latter type. More intriguing and complicated clusters may consist of different kinds of molecules of more or less equal molar ratio, which correspond to the mixed solution when the number of molecules becomes very large. In this situation. a variety of confonmers of different molar ratios may be produced with interesting structural and thermodynamic properties. Studying this type of mixed clusters may help elucidate the property of the solution. for example, the nature of miscibility. in terms of the detailed interactions between the functional groups of the molecules. The properties of this type of mixed clusters in general cannot be expressed as a weighted average of those of the constituent molecules, since they may be determined by

aPresent address: Department of Chemistry. Korea Advanced Institute of Science and Technology. Daejeon 305-701. Korea complicated interactions between the molecules. Thus. one may not employ the polarizable continuum model $(\mathrm{PCM})^{18}$ type methods in which the solvents are treated as continum represented by macroscopic properties such as the dielectric constant. Instead, one may study the interactions among the solvent molecules in detail on the molecular scale by taking advantage of the cluster model. Because of the recent advances in the spectroscopic tecluique (for example. supersonic beam teclunique and UV-IR double resonance method) for examining the structures of the clusters. systematic computational study may yield invaluable information for the structures of this type of mixed clusters and also of the mixed solution, when compared with the experimental observations.

The most useful experimental parameter for elucidating the structures of the clusters is the infrared (IR) frequency of the specific mode in the clusters, and numerous studies on the structure of clusters have focused on the IR frequency shift of the stretching mode involved in hydrogen bonding Most of these studies were centered on the frequency of the proton-donating bond in the clusters. The frequency of the alcoholic $\mathrm{OH}$ group, for example. has proved extremely efficient to study the structure of the hydrogen bonding in alcohol - water clusters. In the "usual" type of hydrogen bond. the $\mathrm{OH}$ stretching frequency in the cluster red-shifts from that in the free molecule. as the result of weakening of the $\mathrm{OH}$ group due to the hydrogen bonding. Hobza and coworkers ${ }^{19}$ however observed that. in some cases. the IR frequency of $\mathrm{X}-\mathrm{H}$ stretching mode in $\mathrm{X}-\mathrm{H} \cdots \mathrm{Y}$ type hydrogen bonding might rather blue-shift. They suggested that the "improper blue-shifting hydrogen bond" may result from the partial electron transfer from the proton-accepting group (Y) to chemical bond(s) in the proton-donating moiety other than $\mathrm{X}-\mathrm{H}$. strengthening and shortening the $\mathrm{X}-\mathrm{H}$ bond. On the other hand, the IR frequency shift of the proton - 
accepting bond ( $\mathrm{C} \equiv \mathrm{N}$ in the present study) has rarely been sy stematically considered so far. Observing this other half of the hydrogen bonding may be quite interesting, because, if the proton-donating bond exhibits a variety of different pattern in the IR frequency shift depending on the nature of interactions, the proton-accepting moiety may also show very interesting behavior. revealing more detailed information of the interactions in the clusters. If the direction of the IR frequency shift depends on some structural characteristic of the cluster. it may give very useful tool for elucidating the structure of the cluster.

In this work, we study the acetonitrile - water clusters to examine the nature of interactions in the mixed clusters in detail. Although the water and the acetonitrile liquids mix very well in all proportions, they do not intermingle on the molecular basis. The structure of the acetonitrile (a typical aprotic solvent) - water (the most well-known protic solvent) solution $^{30.23}$ may rather be described as the intermixture of chisters consisting of a few tens of each molecular species. Since the focus in this work is on the interactions between different kinds of "solvent" molecules in the mixed clusters. our calculated results may help elucidate the structures and the nature of interactions in the mixed clusters to probe the structure of the solution phase ${ }^{2}$ We calculate a variety of conformers, either of $\sigma$-type ( $-\mathrm{OH}$ and $-\mathrm{CN}$ binding linearly) or $\pi$-type ( $-\mathrm{OH}$ and $-\mathrm{CN}$ binding perpendicularly). We calculate that the IR frequency of the proton-accepting $C \equiv N$ stretching mode red-shifts in the $\pi$-type clusters and bheshifts in $\sigma$-type conformers.

\section{Computational Methods}

In this study all the calculations were carried out using the GAUSSIAN 03 set of programs. ${ }^{24}$ The structures and the harmonic frequencies of the clusters are calculated along with the zero-point energies by employing the density functional theory method BLYP ${ }^{250}$ with the basis set $6-31+\mathrm{G}^{* *}$ that has proved to give accurate infrared frequencies for high frequency stretching modes. agreeing very well with the experimental values usually to within $30 \mathrm{~cm}^{-1}$ without employing the scaling factors. The stationary conformers are


Figure 1. Structures and shift of $\mathrm{C}-\mathrm{N}$ stretching trequencies $\left(\mathrm{cm}^{-1}\right)$ of $\left(\mathrm{CH}_{3} \mathrm{CN}\right)-\left(\mathrm{H}_{2} \mathrm{O}\right)_{4}$ clusters.

obtained by verifying that all the hamonic frequencies are real. The binding energies are computed as the difference between the energy of the clusters and the sum of the energies of the separated fragments with zero-point energy correction. Basis set superposition errors ${ }^{27}$ are not considered in the present work. although it may slightly affect the calculated structures.

\section{Results}

$\mathrm{CH}_{3} \mathrm{CN}-\left(\mathrm{H}_{2} \mathrm{O}\right)_{n}(\mathrm{n}=4,8)$ cluster: Figure 1 and Figure 2 present the structures of (acetonitrile) $)_{1}$ (water $)_{n}(n=4.8)$ clusters, respectively, along with their relative energies. The calculated energies and harmonic frequencies are given in Table 1 and Table 2. The BLYP/6-31+G** method employed in this work gives the frequency of the CN stretching mode in agreement with experiments. ${ }^{2}$ Some structures are $" \sigma$-type", whereas others are " $\pi$-type $" .93$ We predict four



(1-8a)



$E=-0.54$
$\Delta v_{\mathrm{CN}}=+17.1$

(1-8b)

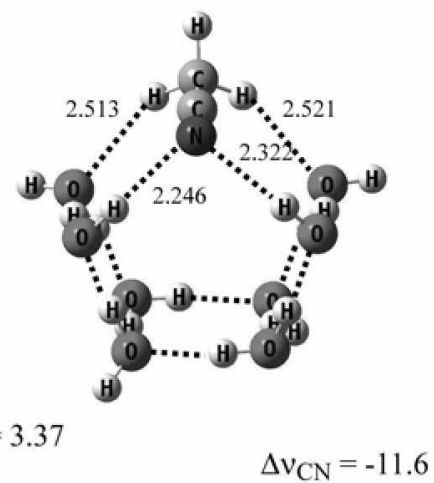

(1-8c)

Figure 2. Structures and shift of $\mathrm{C}-\mathrm{N}$ stretching frequencies $\left(\mathrm{cm}^{-1}\right)$ of $\left(\mathrm{CH}_{3} \mathrm{CN}\right)-\left(\mathrm{H}_{2} \mathrm{O}\right)_{3}$ clusters 
Table 1. Electronic energy ( $\mathrm{E}$ ), zero-point energy ( $\mathrm{ZPE}$ ), relative energy ( $\triangle \mathrm{E}$ ), binding energy $(\mathrm{BE}$ ), and dipole moments of the clusters

\begin{tabular}{|c|c|c|c|c|c|}
\hline & $\begin{array}{c}E \\
\text { (hartree) }\end{array}$ & $\begin{array}{c}\text { ZPE } \\
(\mathrm{kcal} / \mathrm{nnol})\end{array}$ & $\underset{(\mathrm{kcal} / \mathrm{mol})}{\Delta \mathrm{E}}$ & $\begin{array}{c}\mathrm{BE} \\
(\mathrm{kcal} / \mathrm{mol})\end{array}$ & $\begin{array}{c}\text { Dipole moment } \\
\text { (Debye) }\end{array}$ \\
\hline \multicolumn{6}{|l|}{$\left(\mathrm{CH}_{3} \mathrm{CN}\right)_{l}-\left(\mathrm{H}_{2} \mathrm{O}\right)_{\lambda}$} \\
\hline $1-4 a$ & -438.43751 & 88.9 & 0 & 25.387 & 3.8375 \\
\hline$l-4 b$ & -438.43756 & 88.7 & -0.203 & 25.59 & 5.3765 \\
\hline $1-4 c$ & -438.42288 & 86.8 & +7.080 & 18.307 & 0.9767 \\
\hline $1-4 d$ & -438.43589 & 88.0 & -0.117 & 25.504 & 1.2425 \\
\hline \multicolumn{6}{|l|}{$\left(\mathrm{CH}_{3} \mathrm{CN}\right)_{l}-\left(\mathrm{H}_{2} \mathrm{O}\right)_{8}$} \\
\hline $1-8 a$ & -744.17766 & 152.7 & 0 & 60.45 & 3.7826 \\
\hline $1-8 b$ & -744.17788 & 152.3 & -0.54 & 60.99 & 5.8533 \\
\hline $1-8 c$ & -744.17054 & 151.6 & +3.37 & 57.08 & 3.9840 \\
\hline \multicolumn{6}{|l|}{$\left(\mathrm{CH}_{2} \mathrm{CN}\right)_{2}-\left(\mathrm{H}_{2} \mathrm{O}\right)_{2}$} \\
\hline $2-2 a$ & -418.29636 & 85.3 & 0 & 14.6 & 0.0334 \\
\hline $2-2 b$ & -418.29395 & 85.9 & +2.1 & 12.5 & 2.3298 \\
\hline $2-2 c$ & -418.29552 & 86.1 & +1.4 & 13.2 & 5.7683 \\
\hline $2-2 d$ & -418.29337 & 85.8 & +2.5 & 12.1 & 5.7009 \\
\hline \multicolumn{6}{|l|}{$\left(\mathrm{CH}_{3} \mathrm{CN}\right)_{-}-\left(\mathrm{H}_{s} \mathrm{O}\right)_{4}$} \\
\hline $2-4 a$ & -571.16335 & 117.6 & 0 & 29.8 & 0.8605 \\
\hline $2-4 b$ & -571.15980 & 117.0 & +1.63 & 28.2 & 7.4738 \\
\hline
\end{tabular}

conformers of (acetonitrile) $)_{1}$ (water $)_{4}$ clusters. of which (1$4 b)$ is of the lowest energy. The structures $(1-4 a)$ and $(1-4 d)$ are, however, very close in energy to (1-4b). The acetonitrile molecule in (1-4a) is bound to the water tetramer whose structure is approximately square. The structure of (1-ta). which is slightly $(0.2 \mathrm{kcal} / \mathrm{mol})$ higher in energy than (1-4b), is different in the position of the acetonitrile molecule binding to the water tetramer. In the conformer $(1-4 c)$. the acetonitrile molecule is inserted into the water tetramer, thus its energy is significantly ligher than (1-4a) and (1-4b). We reported in a previous paper that for the s-type $1: 1$ isomer the CN stretching is blue-shifted from that of the bare acetonitrile, whereas it is red-shifted for the $\pi$-type cluster. ${ }^{30}$ Sinilar trend is also seen for $\mathrm{CH}_{3} \mathrm{CN}-\left(\mathrm{H}_{2} \mathrm{O}\right)_{4}$ clusters depicted in Figure 1. The $\sigma$ type isomers $(1-4 d)$ and $(1-4 b)$ exhibit blue shifts of 5.4 and $15.5 \mathrm{~cm}^{-1}$, respectively. whereas the $\mathrm{CN}$ frequencies are red-shifted for the $\pi$-type clusters ( $1-4 \mathrm{a})$ and (1-4c) by 3.7 and $20.8 \mathrm{~cm}^{-1}$. respectively.

Since the size of the acetonitrile molecule is larger than the water molecule. its location in the (acetonitrile) - (water) \& clusters may be interesting. The corresponding situation in the solution phase is dilute aqueous solution of acetonitrile. We focus on (acetonitrile) $)_{1}$ - (water) \& clusters (Fig. 2). We find three typical structures of the (acetonitrile) ${ }_{1}$ - (water) 8 clusters, although there certainly will exist much more conformers. The two lowest energy structures are calculated to be of very similar energy: In (1-8a) the acetonitrile molecule binds roughly parallel to the water octamer. The latter water octamer in the cluster seems to correspond to the cubic water octamer predicted by other investigators. In the isomer (1-8b). the acetonitrile molecule binds linearly to the water octamer. The third conformer (1-8c) looks like a pentapole. with the acetonitrile molecule inserted into the water octamer. We observe that the $\mathrm{CN}$ stretching frequencies exhibit behavior that is similar to the (acetonitrile) $)_{1}$ (water) ${ }_{4}$ clusters: in (1-8b) it significantly blue-shifts $\left(17.1 \mathrm{~cm}^{-1}\right)$.
Table 2. Calculated $\mathrm{CN}$ harmonic frequencies ${ }^{a}\left(\mathrm{~cm}^{-1}\right)$

\begin{tabular}{|c|c|}
\hline $\mathrm{CH}_{3} \mathrm{CN}$ & $2260.7[2253]^{b}$ \\
\hline \multicolumn{2}{|l|}{$\left(\mathrm{CH}_{3} \mathrm{CN}\right)_{l}-\left(\mathrm{H}_{2} \mathrm{O}\right)_{4}$} \\
\hline l-la & $22570(-3.7)]^{\circ}$ \\
\hline $1-4 b$ & $2276.2(+15.5)$ \\
\hline $1-4 c$ & $2239.9(-20.8)$ \\
\hline $1-1 d$ & $2266.1(+5.4)$ \\
\hline \multicolumn{2}{|l|}{$\left(\mathrm{CH}_{3} \mathrm{CN}\right)_{1}-\left(\mathrm{H}_{2} \mathrm{O}\right)_{8}$} \\
\hline $1-8 a$ & $2256.8(-3.9)$ \\
\hline $1-8 b$ & $2277.8(+17.1)$ \\
\hline $1-8 c$ & $2249.1(-11.6)$ \\
\hline \multicolumn{2}{|l|}{$\left(\mathrm{CH}_{3} \mathrm{CN}\right)_{2}-\left(\mathrm{H}_{2} \mathrm{O}\right)_{2}$} \\
\hline \multirow[t]{2}{*}{$2-2 a$} & $2265.5(+4.8)$ \\
\hline & $2265.8(+5.1)$ \\
\hline \multirow[t]{2}{*}{$2-2 b$} & $2253.0(-7.7)$ \\
\hline & $2255.9(-4.8)$ \\
\hline \multirow[t]{2}{*}{$2-2 c$} & $2255.5(-5.2)$ \\
\hline & $2255.9(-4.8)$ \\
\hline \multirow[t]{2}{*}{$2-2 d$} & $2250.3(-10.4)$ \\
\hline & $2273.1(+12.4)$ \\
\hline \multicolumn{2}{|l|}{$\left(\mathrm{CH}_{3} \mathrm{CN}\right)_{2}-\left(\mathrm{H}_{2} \mathrm{O}\right)_{4}$} \\
\hline $2+1 a$ & $2251.7(-9.0)$ \\
\hline $2-16$ & $2275.7(+15.0)$ \\
\hline
\end{tabular}

${ }^{a}$ BLYP:6-31-G(d.p). ${ }^{b}$ experiment (Ref. 18). " frequency shift

whereas those in (1-8a) and (1-8c) shift to the red (by 3.9 . $11.6 \mathrm{~cm}^{-1}$ ), characterizing the $\sigma$-type and the $\pi$-type hydrogen bonding between $\mathrm{CH}_{3} \mathrm{CN}$ and the water cluster. These predictions may be useful for elucidating the relative orientation of acetonitrile at the interface between the water and the acetonitrile clusters in the bulk phase.

$\left(\mathrm{CH}_{3} \mathrm{CN}\right)_{2}-\left(\mathrm{H}_{2} \mathrm{O}\right)_{\mathrm{n}}(\mathrm{n}=\mathbf{2 , 4})$ cluster. Figure 3 depicts the structures of the acetonitrile - water cluster in which the molar ratio is $2: 2$. We find four isomers. each of which displays very interesting pattern of hydrogen bonding. The lowest energy conformer is $(2-2 a)$, in which the four mole- 

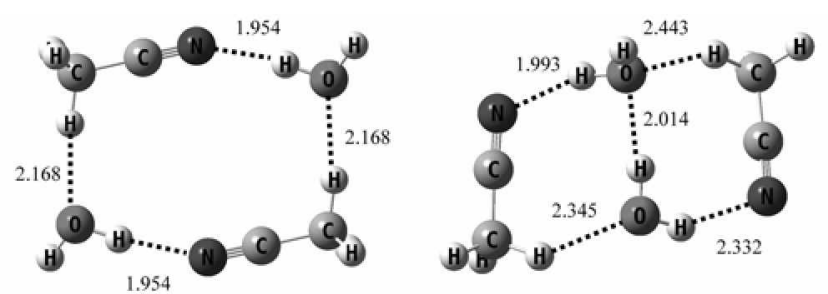

$\mathrm{E}=0$

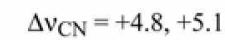

$\mathrm{E}=2.1 \quad \Delta v_{\mathrm{CN}}=-7.7,-4.8$

$(2-2 a)$


$\mathrm{E}=1.4$

$$
\Delta v_{\mathrm{CN}}=-5.2,-4.8 \quad \mathrm{E}=2.5
$$

$\Delta v_{\mathrm{CN}}=-10.4,+12.4$

(2-2c)

(2-2d)

Figure 3. Structures and shift of $\mathrm{C}-\mathrm{N}$ stretching frequencies $\left(\mathrm{cm}^{-1}\right)$ of $\left(\mathrm{CH}_{3} \mathrm{CN}\right)_{2}-\left(\mathrm{H}_{2} \mathrm{O}\right)_{2}$ clusters.

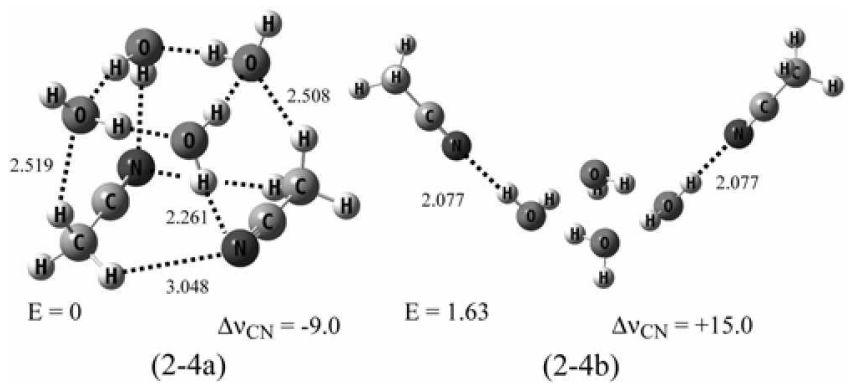

Figure 4 . Structures and shift of $\mathrm{C}-\mathrm{N}$ stretching frequencies $\left(\mathrm{cm}^{-1}\right)$ of $\left(\mathrm{CH}_{3} \mathrm{CN}\right)_{2}-\left(\mathrm{H}_{2} \mathrm{O}\right)_{4}$ clusters.

cules form a ring. This structure looks like two 1:1 clusters binding in head-to-tail fashion. The $\mathrm{CN}$ stretching frequencies blue-shift by $\sim 5 \mathrm{~cm}^{-1}$, indicating $\sigma$-type hydrogen bonding. The other three lowest energy conformers of the (acetonitrile) - (water) 2 type cluster are of similar energy. In (2-2b) and (2-2c). two water molecules fom strong hydrogen bond. while the two acetonitrile molecules bind to the different sides of the water dimer. In (2-2b) the acetonitrile molecules are aligned in opposite direction. while those of (2-2c) align in the same direction. The stretching frequencies of the two $\mathrm{CN}$ bonds red-shift by $4.8-7.7 \mathrm{~cm}^{-1}$. The fourth conformer $(2-2 \mathrm{~d})$ is quite interesting because the two acetonitrile molecules bind to the water dimer in different fashion: one acetonitrile molecule binds only to the proton in one water molecule in linear fashion ( $\sigma$-type), while the other binds to the water dimer parallelly ( $\pi$-type). This difference in the character of hydrogen bonding gives disparate pattern for the C-N stretching frequencies in the cluster $(2-2 \mathrm{~d})$ : the $\mathrm{C}-\mathrm{N}$ stretching mode representing the hydrogen bond between the "free" $\mathrm{CH}_{3} \mathrm{CN}$ moiety and the $\left(\left(\mathrm{H}_{2} \mathrm{O}\right)_{2} \cdot \mathrm{CH}_{3} \mathrm{CN}\right)$ cluster and shifts $+12.4 \mathrm{~cm}^{-1}$, whereas that between the "entbedded" $\mathrm{CH}_{3} \mathrm{CN}$ and the water dimer shifts by -10.4 $\mathrm{cm}^{-1}$.

Finally, the calculated isomers of the (acetonitrile): (water) 4 cluster are depicted in Figure 4 . Of the two structures, $(2-4 a)$ is of lower energy. Two acetonitrile molecules in (2-4a) form a dimer, whereas they bind separately in (2$4 b)$. The $\mathrm{CN}$ stretching frequencies in (2-4a) and (2-4b) shift in opposite directions $\left(-9.0\right.$ and $\left.+15.0 \mathrm{~cm}^{-1}\right)$, respectively, as may now be easily predicted by the type of hydrogen bonding as discussed above.

Acknowlegments. This work was supported by the Korea Research Foundation Grant (KRF-2006-311-C00078).

\section{References}

1. Zwier. T. S. Amm. Rev Phus. Chem 1996, $47,205$.

2. Castleman, A. W: Bowen. K. H. d. Phus. Chem. 1996. 100. 12911.

3. (a) Ahn. D.-S.: Park. S.-W.: Jeon. I.-S.: Lee. M.-K.: Kim. N.-H.: Hant. Y.-H.: Lee. S. J. Phos Chem. B 2004. 107. 14109. (b) Aht1. D.-S.: Kang. A.-R.: Lee. S.: Kim, B.; Kim, S. K.: Neuhauser. D. J. Chem. Phys. 2005, 122. 084310 .

4. Barth. H.-D:: Buchhold. K.: Djatari. S.: Reimann, B: Lommatzsch. U.: Brutschy. B. Chem. Phns. 1998. 239. 49.

5. Auspurger. T. D.: Dykstra. C. E.: Zwier. T. S.: J. Phus Chent. 1993. 97.980

6. Hredericks. S. Y.: Iordan. K. D.: Zwier. T. S. J. Phws. Chem. 1996. 100.7810 .

7. Garrett, A. W.: Zwier, T. S. J. Chem. Phys. 1992, 96, 3402.

8. Lee. K. T: Sung, J.: Lee. K. J.: Kim, S. K.: Park, Y. D. J. Chem. Phos 2002. 116.8251.

9. (a) Aht1. D.-S.: Lee. S.: Kim. B. Chem. Phws. Lett 2004. 390.384 (b) Lee. K.-M.: Park. S.-W.: Jeon1. I.-S.: Lee. B.-R.: Ahn1. D.-S.: Lee. S. Bull. Kowam Chem. Soc. 2005. 26.909.

10. Janzen, Ch: Spangenterg. D.: Roth, W: Kleinermanns. K. J. Chem. Phys. 1999, 110, 9898

11. (a) Ahn. D.-S.: Park. S.-W: Lee. S.: Kim. B. J. Phns. Chem. A 2003. 107. 131. (b) Ahn1. D.-S.: Lee. S.: Cheong. W. J. Bull. Korem Chem. Soc. 2004. 25. 1161

12. Ebata, T: rujii. A.: Mikami, N. Int Rev Phus. Chem 1998, 17. 331 .

13. Gerhards, M.: Kleinermanns. K. J. Chem. Phys. 1995. 103 7392.

14. Feller. D.: Feyereisen. M. W. J. Conp. Chent. 1993. It. 1027.

15. Kryachlo. E. S.: Nguyen. M. T. J. Chem. Phys. 2001. 115.833.

16. Ishikata, S.; Ebata, T; Mikami, N. J. Chem. Plo's. 1999. 110. 9504.

17. El-Shall, M. S.; Daly. G. M.; Wright. D. J. Chem. Phys. 2001. 116. 10253

18. Cramer. C. T.: Truhlar. D. G. Chent. Rev: 1999.99.2161.

19. Hobza. P.: Havlas. Z. Chem. Rev: 2000. 100. 4253

20. Jamroz. D; Stangret. J.: Lindgren, J. J. Am. Chem. Soc. 1993. 115. 6165 .

21. Rowlen. K. L.: Harris. J. M. Anal Chem 1991, 63, 964.

22. Shin. D.: Wijnet1. I. W.: Engberts. J. B. H. N.: Wakisaka. A. J. Phts. Chem. B 2002. 106.6014.

23. Kovacs. H.: Laaksonet1. A. J. Am. Chen. Soc. 1991. M3. 5596.

24. Frisch. M. J.: Trucks. G. W; Schlegel. H. B.: Scuseria, G. E: Robb. M. A.: Cheeseman, J. R; Montgomery. JI., J. A.; Vreven. T.: Kudin, K. N.; Burant, J. C.: Millam, J. M. Iyengar. S. S. Tomasi. J.: Barone. V: Mennucei. B.: Cossi. M.: Scalmani. G: Rega. N.: Petersson. G. A.: Nakatsuij. H.: Hada. M.: Ehara. M.: Toyota. K.: Fukuda. R.: Hasegawa. J.: Ishida. M.: Nahajima. T.: Honda, Y; Kitao. O.: Nakai. H.; Klene, M. Li, X: Knox. J. E.; Hratchian, H. P.: Cross, J. B.; Bakken. V.: Adamo, C.: Jaramillo. 
J.: Gomperts. R.: Stratmann. R. E.: Yazyev. O.: Austin. A. J.: Cammi. R.: Pomelli. C.: Ochterski. J. W.: Ayala. P. Y.: Morokuma. K.: Voth. G. A.: Salvador. P.: Dannenberg. J. J.: Zakrzewski. V. G. Dapprich. S.: Daniels. A. D.: Strain, M. C.: Farkas, O.: Malick. D. K.: Rabuck A. D.: Raghavachari K.: Foresman J. B.: Ortiz. I. V.: Cui, Q: Baboul. A. G. Clifford, S. Cioslowski. I.: Stefanov. B. B.: Liu. G.: Liashenko. A.: Piskorz. P.: Komaromi. I.: Martin. R. L.: Fox. D. J.: Keith. T.: Al-Laham. M. A.: Peng. C. Y: Nanavakkara. A.: Challacombe. M.: Gill. P. M. W. Johnson. B.: Chen, W: Wong, M. W: Gonzalez. C.: Pople, J. A.: Gaussian.
It1c:: Wallingford. CT. $200(4)$

25. Becke. A. D. Plns. Rev A 1988. 38. 3098

26. Lee. C.: Yang. W.: Parr. R. P. Phrs. Rev: $B$ 1988. 37. 785.

27. Park. Y. C. Lee, J. S. Bull. Korean Chem Soc, 2007, 28, 386

28. Ishikawa, S.; Ebata, T; Mikami, N. J. Chem. Plos. 1999. 110. 9504.

29. (a) Kimn. K. S.: Tarakeshwar. P.: Lee. T. Y. Chem. Rev: 2000. 100. 4145. (b) Kim. K. S.: Taraheshwar. P.: Lee. J. Y. Chent. Rev 2000. 100.4145

30. Ahn. D.S.; Lee, S. Bull. Korean Chem. Soc. 2003. 24, 545. 